\title{
Economic Evaluation of Foliar NPK Fertilizer on Tea Yields in Kenya
}

\author{
Rachael Njeri E. Njogu ${ }^{1}$, David K. Kariuki ${ }^{1}$, David M. Kamau ${ }^{2} \&$ Francis N. Wachira ${ }^{2}$ \\ ${ }^{1}$ Department of Chemistry, University of Nairobi, Nairobi, Kenya \\ ${ }^{2}$ Tea Research Foundation of Kenya, Kericho, Kenya \\ Correspondence: David K. Kariuki, School of Physical Sciences, Department of Chemistry, University of \\ Nairobi, Nairobi, Kenya. Tel: 254-722-831-418. E-mail: kkariuki@uonbi.ac.ke
}

Received: October 8, 2014 Accepted: January 14, 2015 Online Published: February 3, 2015

doi:10.5539/jps.v4n1p35 URL: http://dx.doi.org/10.5539/jps.v4n1p35

\begin{abstract}
Economic evaluation analysis of foliar (NPK) fertilizer on tea yields was investigated on three varieties of tea grown in the Kenyan Highlands. Foliar fertilizers trial was setup on three sites, Meru, Kirinyaga and Kericho, comprising of 36 plots per site. Two foliar fertilizer types, Foliar Fertilizer 1 (FF1) and Foliar Fertilizer 2 (FF2), a positive control of Soil Fertilizer (SF) and a blank (FF0) were used to standardize the method. Yield analysis in Meru site showed significant increase (HSD $=4.9, \mathrm{p} \leq 0.05)$ after $\mathrm{FF} 1$ full rate application. SF had significant yield increases for all its rates from zero rate $(\mathrm{HSD}=49,44,19, \mathrm{p} \leq 0.05)$ for half, full and double rates respectively. FF2 had no yield increase after its application. The economic rates were determined to be full rate for FF1 and SF and half rate for FF2 in Kericho site; half rate for all fertilizer types Kirinyaga site; double rate for FF2 and SF and full rate for FF1 in Meru site. The profitable rates were: double rate for SF across all sites and for FF1 and FF2 in Meru site; full rate for FF1 and half rate for FF2 in Kericho and Kirinyaga sites respectively.
\end{abstract}

Keywords: tea, yields, economic evaluation, foliar fertilizer

\section{Introduction}

Tea, Camellia sinensis, is the second largest foreign exchange earner hence contributes significantly, 107 billion in 2011, to the Kenyan economy (TBK, 2010). Fertilizer is the second largest tea production cost item after plucking with significant bearing on both yield and quality of tea. Fertilizers increase the growth rate and density of harvested shoots thereby increasing yields (TRFK, 1999). Different tea clones have different genetic potentials to yield and response to nutrients supply. However, the fertilizers applied to the soil either is lost, by being bound by soil or are washed out of the root zone (Njogu et al., 2014a). In addition, nutrient imbalances for tea in the soil occur, rendering the soils moribund hence unsustainable for tea production (Ayiemba \& Nyabundi, 2010). Experiments have shown that foliar fertilizer application can increase yield from 12 to 25 percent when compared to soil fertilizer application (Islam et al., 2012).

Tea productivity is quantified in terms of the weight of 'made tea' per unit land area per year. 'Made tea' is obtained after the harvested shoot has gone through the manufacturing process (De Costa et al., 2007), and the weight is directly related to the fresh weight of plucked shoot (2-3 leaves and a bud) by a factor of 0.225 (Anon, 2002). Therefore, yield components of tea are the number of plucked shoots per unit land area and the mean weight per shoot (De Costa et al., 2007).

Fertilizer recommendations are primarily based on field trials that determine the crop response (yield responses) to various rates of fertilizer applications and must optimize crop yield and quality, maximize profitability and reduce the risk of environmental pollution (Belanger et al., 2000). Data from the trials are fitted to several statistical models to describe relationships between $\mathrm{N}$ rates and yields, and solving the models to identify the economic optimum rates (EORs) (Kyveryga et al., 2007). The economic optimum rate is arrived at the point where the marginal cost (MC) of the fertilizer is equal to the marginal revenue (MR) per unit fertilizer (MC=MR) (Kiprono et al., 2010; Kyveryga et al., 2007). The EORs can differ with the growing conditions, locations and the clones and hence, it is important to consider the factors in the local environment that may influence production. These include yield trends and seasonal variations in a particular site. Factors affecting yields include soil properties, site, rainfall, genetic material and age of tea, year of prune, fertilizer types, rates and frequency of application (TRFK, 1999). The combination of these components allow for the estimation of the economically optimum Nitrogen rate (EONR) (Kiprono et al., 2010). To achieve the most with the 
recommended EONRs some factors are considered; current practice whereby EOR is more often below the current practice and use of proven crop production practices e.g. maintaining soil $\mathrm{pH}, \mathrm{P}$ and $\mathrm{K}$ levels at optimum levels (Kiprono et al., 2010). Several studies have demonstrated the yield benefits of nitrogenous fertilizers in tea (Ayiemba \& Nyabundi, 2010). The rate of $\mathrm{N}$ fertilizer applied to tea to achieve maximum profit shifts downward when the price of $\mathrm{N}$ fertilizer increases. The best rate of $\mathrm{N}$ to apply is the economic optimum since the last unit of $\mathrm{N}$ fertilizer added would result in additional yield hence paying its cost. This rate maximizes the profits obtained per unit area to farmer (Kiprono et al., 2010).

Production function relates the maximum quantity of output that can be produced given the quantities of the inputs employed and is expressed as;

$$
Q=f(L, K)
$$

Where $\mathrm{Q}$ is the quantity of output, $\mathrm{L}$ is the quantity of labor used, and $\mathrm{K}$ is the quantity of capital employed. The maximum quantity of output depends on the quantities of labor and capital employed. This function shows the maximum total physical product (TPP) that can be obtained using different combinations of quantities of inputs. Two other important concepts are the average physical product (APP) which is the output-input ratio for each level of variable input usage $(\mathrm{APP}=\mathrm{Q} / \mathrm{L})$, and the marginal physical product (MPP) of an input which is the addition to TPP resulting from the addition of one unit of input, when the amounts of other inputs are constant and is expressed as MPP $=\Delta \mathrm{Q} / \Delta \mathrm{L}$. There are three stages involved in production; (1) increasing marginal returns where increase in inputs increase the output (TPP) at an increasing rate, (MPP $>0$, APP is rising and MPP $>$ APP), (2) diminishing marginal returns whereby increase in inputs still increases total output but at a decreasing rate, (MPP $>0$, but APP is falling, MPP $<$ APP), and (3) diminishing total returns where increase in input decreases total output (MPP $<0$, TPP is falling). Stage 2 is the relevant part of the production function for profitable production to take place (Colman \& Young, 1989). To characterize productivity of inputs, marginal and average products are used where average physical product (APP), is the amount of output per unit of labor while marginal physical product (MPP) is the rate at which total output changes as the quantity of input is changed.

The level of physical output cannot always be used to predict the optimum fertilizer ratios to be used. Therefore, to determine the highest profit ratio or economic optimum fertilizer ratio to use, TPP, MPP, and APP are translated into total value product (TVP), marginal value product (MVP), and average value product AVP by multiplying the output by the market price of made tea being the current average auction price per kilogram $(\mathrm{Kg})$ of made tea (Kiprono et al., 2010). Sustainability in tea production can be ensured by utilization of optimum amounts of fertilizers and this can be achieved through application of nutrients through foliage rather than soil, which has not been tested in Kenya. Moreover, no economic evaluation of foliar fertilizers has been done in tea production in Kenya.

\section{Methodology}

\subsection{Experimental Sites}

The trial was set up in September 2010, and comprised of three experimental sites which represent the geographically different major tea growing regions in Kenya (East and West of the Great Rift Valley) -Timbilil estate, TRFK, Kericho, clone TRFK 31/8; KTDA-Kangaita farm, Kirinyaga, clone TRFK 6/8; Michimikuru Ltd Co. farm, Meru, clone EPK D99/10. Each site comprised of 36plots laid in a randomized complete block design with three replications of three fertilizer types; two NPK foliar fertilizers (FF1 and FF2) and the convectional NPK soil applied fertilizer (SF).

Table 1. Location, elevation and climatic characteristics of experimental sites

\begin{tabular}{ccccccc}
\hline Site & Clone & Latitude & Longitude & $\begin{array}{c}\text { Elevation } \\
(\mathrm{m})\end{array}$ & $\begin{array}{c}\text { Mean Annual Temp } \\
\left({ }^{\circ} \mathrm{C}\right)\end{array}$ & $\begin{array}{c}\text { Mean Annual Rainfall } \\
(\mathrm{mm})\end{array}$ \\
\hline Kericho & TRFK 31/8 & $0^{\circ} 22^{\prime} \mathrm{S}$ & $35^{\circ} 32^{\prime} \mathrm{E}$ & 2180 & 16.6 & 2175 \\
Kirinyaga & TRFK 6/8 & $0^{\circ} 26^{\prime} \mathrm{S}$ & $37^{\circ} 15^{\prime} \mathrm{E}$ & 2020 & 15.5 & 2040 \\
Meru & $\mathrm{EPK}$ & $0^{\circ} 11^{\prime} \mathrm{N}$ & $37^{\circ} 51^{\prime} \mathrm{E}$ & 1950 & 17.3 & 2379 \\
\hline
\end{tabular}

* Source: Tea Research Foundation of Kenya weather reports. 


\subsection{Fertilizers and Their Application Rates}

Two foliar fertilizers and one soil applied fertilizer were used in the fertilizer trial; Maj Tea foliar fertilizer, a water soluble formulation with the elemental composition; NPK 24:24:18 + Trace elements $0.9 \mathrm{MgO}, 0.1625$ $\mathrm{Fe}(\mathrm{EDTA}), 0.16 \mathrm{Cu}, 0.08 \mathrm{Zn}, 0.0325 \mathrm{~B}, 0.0012 \mathrm{Mo}$, and $0.08 \mathrm{Mn}$ (EDTA). The $\mathrm{pH}$ of a $10 \%$ solution was 3-4, with a density of 1.40; T-foliar SPS fertilizer and plant booster containing NPK 20:5:5 $+\mathrm{S}+\mathrm{MgO}+$ Trace Elements; and the soil chemically compounded fertilizer containing NPK 25:5:5. The fertilizers were coded as Foliar Fertilizer 1 (FF1) for Maj Tea foliar, Foliar Fertilizer 2 (FF2) for T-foliar and Soil Fertilizer (SF) for NPK 25:5:5. FF1 was applied at a rate of 1 liter per hectare every 2 months, FF2 at a rate of 3liters per hectare every 3 months and SF applied once per year. These were considered as the Full rates of application for the respective foliar fertilizers.

The application rates for the respective foliar fertilizers were varied; Nil, Half rate, Full rate and Double rates and respectively coded as, $\mathrm{FF} 1_{0}, \mathrm{FF} 1_{1 / 2}, \mathrm{FF} 1_{1}, \mathrm{FF} 1_{2}$, and $\mathrm{FF} 2_{0}, \mathrm{FF} 2_{1 / 2}, \mathrm{FF} 2_{1}, \mathrm{FF} 2_{2}$, for Maj and $\mathrm{T}$ foliar fertilizer respectively, and $0,75,150$, and $225 \mathrm{Kg} \mathrm{N} / \mathrm{ha} /$ year for $\mathrm{SF}$ which was treated as the positive control. The amount of fertilizers applied for both foliar and soil fertilizers were calculated based on the number of bushes per plot and the spacing of the tea bushes. The average amounts applied per plot for each fertilizer type are shown in Table 2.

\subsection{Tea Yield Measurements}

The young flush of two leaves and a bud from the demarcated plots were picked and weighed per plot after every 10 to 14 days, depending on available crop. The weight for green leaf yield of each of the plots was recorded on site and converted to made tea yields using a conversion factor of 0.225 (Anon, 2000).

\subsection{Statistical Analysis}

All the determinations were carried out in triplicate and the data were subjected to one-way analysis of variance (ANOVA) whereby analysis for each variable was separately done i.e. by fertilizer type (Blank, FF1, FF2, and SF) and by rates of application (zero, half, full and double). This was followed by the Tukey-Kramer range test to establish the honest significant difference (HSD) in means between the various group means at $\mathrm{p} \leq 0.05$ confidence level. HSD is minimum distance between two group means that must exist before the difference between the two groups is considered statistically significant.

\subsection{Economic Analysis}

The production parameters of interest were; TPP, APP $=\mathrm{Q} / \mathrm{X}=\mathrm{f}(\mathrm{X}) \mathrm{X}$, and $\mathrm{MPP}=\Delta \mathrm{TPP} / \Delta \mathrm{X}$. TVP, AVP and MVP values were obtained by multiplying the corresponding values of TPP, APP and MPP with 2011's average auction price per Kg of made tea for Kenyan tea, which stood at KES 264.43. In this study, the prices of the treatments were KES $150 / 500 \mathrm{~cm}^{3}$ for FF1, KES $250 / 1000 \mathrm{~cm}^{3}$ for FF2 and KES 3,000 per $50 \mathrm{~kg}$ bag of SF (from KTDA price estimates). Fixed cost of production included the application costs, KES 100 per person per application for any treatment. Assumption was made that two people were used to apply every time.

\section{Results}

\subsection{Tea Yields}

Pair wise comparison of yields by types of fertilizers and rates of applications (Table 3) showed that in Kericho and Meru, there was significant increase in yields between zero fertilizer and $\mathrm{SF}_{1 / 2}, \mathrm{SF}_{1}$ and $\mathrm{SF}_{2}$ with honestly significant difference (HSD) values of 16.8, 16.4 and 10.4 and 49.3, 22.4, 19.3at $\mathrm{p} \leq 0.05$ for Kericho and Meru sites respectively. In Meru site, a significant increase in yields of 4.9 was obtained between zero and $\mathrm{FF}_{1}$ fertilizers. In Kirinyaga site, no significant increases in yields were obtained from any of the fertilizers at the different rates of application. In Kericho, full rates had the highest yield mean difference for FF1 (217 Mt/Ha) as compared to zero rates, while the double rates lead to decreased yields from full rates $(-205 \mathrm{Mt} / \mathrm{Ha})$ which indicates the diminishing returns of FF1 beyond full rates. For FF2, the half rates had the highest yields with a mean difference of $236 \mathrm{Mt} / \mathrm{Ha}$ from zero fertilizer. The full rates and double rates led to decrease yields as compared to half rates of FF2 (-154 Mt/Ha and - 152Mt/Ha respectively) due to diminishing returns of the fertilizer, while SF's half rates had the highest mean difference from zero( $631 \mathrm{Mt} / \mathrm{Ha})$. Full and double rates led to diminished returns when compared to half rates $(-15 \mathrm{Mt} / \mathrm{Ha}$ and $-240 \mathrm{Mt} / \mathrm{H}$ respectively). In Kirinyaga site, half rates had higher yields mean differences for all the fertilizers when compared to the zero rates with diminished returns resulting beyond this rate. In Meru site, full rates had the highest yield mean difference for FF1 (161 Mt/Ha) against zero rates, with double rates showing diminished returns (-90 Mt/Ha). FF2, the double rates had the highest yield mean difference $(327 \mathrm{Mt} / \mathrm{Ha})$ while for $\mathrm{SF}$ the half rates had the highest yield mean 
difference as compared to zero $(890 \mathrm{Mt} / \mathrm{Ha})$ with full and double rates leading to diminished returns $(-485 \mathrm{Mt} / \mathrm{Ha}$ and $-541 \mathrm{Mt} / \mathrm{Ha}$ respectively).

Table 2. Amounts of fertilizer applied

\begin{tabular}{|c|c|c|c|c|c|c|}
\hline \multirow[t]{2}{*}{ Sites } & \multirow[t]{2}{*}{ Treatments } & \multirow[t]{2}{*}{ Rates } & \multirow[t]{2}{*}{ Amounts of fertilizer applied $(\mathrm{g})$} & \multicolumn{3}{|c|}{ Amounts of $\mathrm{N}, \mathrm{P}, \mathrm{K}$ in each rate $(\mathrm{g})$} \\
\hline & & & & $\mathrm{N}(\mathrm{g})$ & $\mathrm{P}(\mathrm{g})$ & $\mathrm{K}(\mathrm{g})$ \\
\hline \multirow[t]{9}{*}{ KERICHO } & \multirow[t]{3}{*}{ FF1 } & Half & 10.5 & 2.5 & 2.5 & 1.9 \\
\hline & & Full & 21 & 5.1 & 5.1 & 3.8 \\
\hline & & Double & 42 & 10.0 & 10.0 & 7.6 \\
\hline & \multirow[t]{3}{*}{ FF2 } & Half & 23 & 4.64 & 1.16 & 1.16 \\
\hline & & Full & 46 & 9.25 & 2.31 & 2.31 \\
\hline & & Double & 92 & 18.5 & 4.63 & 4.63 \\
\hline & \multirow[t]{3}{*}{ SF } & Half & 390 & 97.5 & 19.5 & 19.5 \\
\hline & & Full & 780 & 194.9 & 39.0 & 39.0 \\
\hline & & Double & 1169 & 292.3 & 58.5 & 58.5 \\
\hline \multirow[t]{9}{*}{ KIRINYAGA } & \multirow[t]{3}{*}{ FF1 } & Half & 10.6 & 2.6 & 2.6 & 1.9 \\
\hline & & Full & 22 & 5.2 & 5.2 & 3.9 \\
\hline & & Double & 43 & 10.4 & 10.4 & 7.9 \\
\hline & \multirow[t]{3}{*}{ FF2 } & Half & 23 & 4.64 & 1.16 & 1.16 \\
\hline & & Full & 46 & 9.28 & 2.32 & 2.32 \\
\hline & & Double & 92 & 18.6 & 4.6 & 4.6 \\
\hline & \multirow[t]{3}{*}{ SF } & Half & 418 & 104.5 & 20.9 & 20.9 \\
\hline & & Full & 836 & 209.0 & 41.8 & 41.8 \\
\hline & & Double & 1254 & 313.6 & 62.7 & 62.7 \\
\hline \multirow[t]{9}{*}{ MERU } & \multirow[t]{3}{*}{ FF1 } & Half & 13 & 3.1 & 3.1 & 2.3 \\
\hline & & Full & 26 & 6.1 & 6.1 & 4.6 \\
\hline & & Double & 52.5 & 12.5 & 12.5 & 9.4 \\
\hline & \multirow[t]{3}{*}{ FF2 } & Half & 27 & 5.6 & 1.4 & 1.4 \\
\hline & & Full & 55 & 11.1 & 2.8 & 2.8 \\
\hline & & Double & 111 & 22.3 & 5.6 & 5.6 \\
\hline & \multirow[t]{3}{*}{ SF } & Half & 502 & 125.4 & 25.1 & 25.1 \\
\hline & & Full & 1003 & 250.7 & 50.1 & 50.1 \\
\hline & & Double & 1505 & 376.4 & 75.3 & 75.3 \\
\hline
\end{tabular}


Table 3. Analysis of Yields by types of fertilizer and rates of application in Kericho, Kirinyaga and Meru sites

\begin{tabular}{|c|c|c|c|c|c|}
\hline \multirow[t]{2}{*}{ Site } & \multirow[t]{2}{*}{ Group $\left(\mathrm{X}_{1}\right)$ vs. $\operatorname{Group}\left(\mathrm{X}_{2}\right)$} & \multicolumn{2}{|c|}{ Group Means (Mt/Ha) } & \multirow{2}{*}{$\begin{array}{l}\text { Mean Dif }\left(X_{2}-X_{1}\right) \\
(\mathrm{Mt} / \mathrm{Ha})\end{array}$} & \multirow[t]{2}{*}{ HSD } \\
\hline & & $\mathrm{X}_{1}$ & $\mathrm{X}_{2}$ & & \\
\hline \multirow[t]{18}{*}{ Kericho } & ZERO vs. FF $1_{1 / 2}$ & 1045 & 1115 & 70 & 1 \\
\hline & ZERO vs. $F F 1_{1}$ & 1045 & 1262 & 217 & 3 \\
\hline & ZERO vs. $\mathrm{FF} 1_{2}$ & 1045 & 1057 & 12 & 0 \\
\hline & $\mathrm{FF} 1_{1 / 2}$ vs. $\mathrm{FF} 1_{1}$ & 1115 & 1262 & 147 & 2 \\
\hline & $F F 1_{1 / 2}$ vs. $F F 1_{2}$ & 1115 & 1057 & -58 & 1 \\
\hline & $\mathrm{FF} 1_{1}$ vs. $\mathrm{FF} 1_{2}$ & 1262 & 1057 & -205 & 3 \\
\hline & ZERO vs. FF $2_{1 / 2}$ & 1045 & 1281 & 236 & 2 \\
\hline & ZERO vs. FF $2_{1}$ & 1045 & 1126 & 81 & 1 \\
\hline & ZERO vs. FF $2_{2}$ & 1045 & 1129 & 84 & 1 \\
\hline & $\mathrm{FF} 2_{1 / 2}$ vs. $\mathrm{FF} 2_{1}$ & 1281 & 1126 & -154 & 2 \\
\hline & $\mathrm{FF} 2_{1 / 2}$ vs. $\mathrm{FF} 2_{2}$ & 1281 & 1129 & -152 & 2 \\
\hline & $\mathrm{FF} 2_{1}$ vs. $\mathrm{FF} 2_{2}$ & 1126 & 1129 & 2 & 0 \\
\hline & ZERO vs. $\mathrm{SF}_{1 / 2}$ & 1045 & 1676 & 631 & $16.7996^{*}$ \\
\hline & ZERO vs. $\mathrm{SF}_{1}$ & 1045 & 1661 & 616 & $16.3995^{*}$ \\
\hline & ZERO vs. $\mathrm{SF}_{2}$ & 1045 & 1436 & 391 & $10.4125^{*}$ \\
\hline & $\mathrm{SF}_{1 / 2}$ vs. $\mathrm{SF}_{1}$ & 1676 & 1661 & -15 & 0 \\
\hline & $\mathrm{SF}_{1 / 2}$ vs. $\mathrm{SF}_{2}$ & 1676 & 1436 & -240 & $6.3871^{*}$ \\
\hline & $\mathrm{SF}_{1}$ vs. $\mathrm{SF}_{2}$ & 1661 & 1436 & -225 & $5.9870^{*}$ \\
\hline \multirow[t]{18}{*}{ Kirinyaga } & ZERO vs. FF $1_{1 / 2}$ & 953 & 1003 & 50 & 1 \\
\hline & ZERO vs. FF1 $1_{1}$ & 953 & 931 & -22 & 1 \\
\hline & $\mathrm{ZERO}$ vs. $\mathrm{FF} 1_{2}$ & 953 & 928 & -26 & 1 \\
\hline & $\mathrm{FF} 1_{1 / 2}$ vs. $\mathrm{FF} 1_{1}$ & 1003 & 931 & -72 & 2 \\
\hline & $\mathrm{FF} 1_{1 / 2}$ vs. $\mathrm{FF} 1_{2}$ & 1003 & 928 & -75 & 2 \\
\hline & $\mathrm{FF} 1_{1}$ vs. $\mathrm{FF} 1_{2}$ & 931 & 928 & -3 & 0 \\
\hline & ZERO vs. FF $2_{1 / 2}$ & 953 & 1035 & 82 & 1 \\
\hline & ZERO vs. FF $2_{1}$ & 953 & 868 & -85 & 1 \\
\hline & ZERO vs. FF $2_{2}$ & 953 & 908 & -45 & 1 \\
\hline & $\mathrm{FF} 2_{1 / 2}$ vs. $\mathrm{FF} 2_{1}$ & 1035 & 868 & -167 & 2 \\
\hline & $\mathrm{FF} 2_{1 / 2}$ vs. $\mathrm{FF} 2_{2}$ & 1035 & 908 & -127 & 2 \\
\hline & $\mathrm{FF} 2_{1}$ vs. FF $2_{2}$ & 868 & 908 & 40 & 1 \\
\hline & ZERO vs. $\mathrm{SF}_{1 / 2}$ & 953 & 1241 & 288 & 3 \\
\hline & ZERO vs. $\mathrm{SF}_{1}$ & 953 & 1001 & 48 & 1 \\
\hline & ZERO vs. $\mathrm{SF}_{2}$ & 953 & 1081 & 128 & 2 \\
\hline & $\mathrm{SF}_{1 / 2}$ vs. $\mathrm{SF}_{1}$ & 1241 & 1001 & -240 & 3 \\
\hline & $\mathrm{SF}_{1 / 2}$ vs. $\mathrm{SF}_{2}$ & 1241 & 1081 & -160 & 2 \\
\hline & $\mathrm{SF}_{1}$ vs. $\mathrm{SF}_{2}$ & 1001 & 1081 & 80 & 1 \\
\hline \multirow[t]{2}{*}{ Meru } & ZERO vs. $F F 1_{1 / 2}$ & 988 & 1027 & 39 & 1 \\
\hline & ZERO vs. FF $1_{1}$ & 988 & 1149 & 161 & 4.8984* \\
\hline
\end{tabular}




\begin{tabular}{|c|c|c|c|c|}
\hline ZERO vs. $F F 1_{2}$ & 988 & 1059 & 71 & 2 \\
\hline $\mathrm{FF} 1_{1 / 2}$ vs. $\mathrm{FF} 1_{1}$ & 1027 & 1149 & 121 & 4 \\
\hline$F F 1_{1 / 2}$ vs. $F F 1_{2}$ & 1027 & 1059 & 32 & 1 \\
\hline $\mathrm{FF} 1_{1}$ vs. $\mathrm{FF} 1_{2}$ & 1149 & 1059 & -90 & 3 \\
\hline ZERO vs. FF $2_{1 / 2}$ & 988 & 1019 & 31 & 0 \\
\hline ZERO vs. FF $2_{1}$ & 988 & 1131 & 143 & 2 \\
\hline ZERO vs. FF $2_{2}$ & 988 & 1315 & 327 & 5 \\
\hline $\mathrm{FF} 2_{1 / 2}$ vs. $\mathrm{FF} 2_{1}$ & 1019 & 1131 & 112 & 2 \\
\hline $\mathrm{FF} 2_{1 / 2}$ vs. FF $2_{2}$ & 1019 & 1315 & 296 & 4 \\
\hline $\mathrm{FF} 2_{1}$ vs. $\mathrm{FF} 2_{2}$ & 1131 & 1315 & 184 & 3 \\
\hline ZERO vs. $\mathrm{SF}_{1 / 2}$ & 988 & 1878 & 890 & $49.2607^{*}$ \\
\hline ZERO vs. $\mathrm{SF}_{1}$ & 988 & 1393 & 405 & $22.4275^{*}$ \\
\hline ZERO vs. $\mathrm{SF}_{2}$ & 988 & 1337 & 349 & $19.3243^{*}$ \\
\hline $\mathrm{SF}_{1 / 2}$ vs. $\mathrm{SF}_{1}$ & 1878 & 1393 & -485 & $26.8333^{*}$ \\
\hline $\mathrm{SF}_{1 / 2}$ vs. $\mathrm{SF}_{2}$ & 1878 & 1337 & -541 & $29.9365^{*}$ \\
\hline $\mathrm{SF}_{1}$ vs. $\mathrm{SF}_{2}$ & 1393 & 1337 & -56 & 3 \\
\hline
\end{tabular}

Starred values *represent significant differences at $\mathrm{P} \leq 0.05$.

Pair wise comparison by site showed clone TRFK 31/8 and clone EPK D99/10 had significantly higher yields $(p \leq 0.05)$ than clone TRFK 6/8. Correlation between first mature leaf data and yields are presented in Table 8. In Kericho, yields correlated significantly with $\mathrm{N} \% \mathrm{r}=0.453(\mathrm{p} \leq 0.01)$, showing that $\mathrm{N}$ uptake influenced yields. Nitrogen availability affects yield of tea. Its applications should be carefully managed, particularly in tea, to optimize marketable yield while minimizing environmental effects. Yields increase with higher use of nitrogen up to high levels with proportional increase in economic returns. Similar trends were noted for the other nutrients; with $\mathrm{P} \% \mathrm{r}=-0.332(\mathrm{p} \leq 0.05), \mathrm{K} \% \mathrm{r}=-0.373(\mathrm{p} \leq 0.05)$ and with $\mathrm{Mn} \% \mathrm{r}=-0.372(\mathrm{p} \leq 0.05)$. In Kirinyaga, there were no significant correlations between nutrients and yields.

\subsection{Economic Analysis}

In the economic analysis studies, the economic optimum rate and the most profitable rate for each fertilizer in each site was established for foliar fertilizers (FF1 and FF2) and soil fertilizer (SF) on yield of tea in the three tea growing zones as shown in Table 4. Kericho site: For the SF fertilizer, despite the full rates and the half rates having the same Marginal Physical Product (MPP) value of 3, the Total Value Product (TVP) value for full rates (KES 365,420) was higher than the TVP value for half rates (KES 315,920) hence the full rates was the optimum application rate for this treatment. For FF1, the full rates had the highest MPP, MVP and TVP values: 1.7, 375 and, KES 251,900 respectively, as compared to other rates, hence it was the economic rate of application for this clone. On the other hand, FF2 half rate has the highest MPP, MVP and TVP values: 3.7, 821, and 281,600 respectively, hence it became the economic rate of application for this clone.

For Kirinyaga site, it was observed that for all the treatments applied to this clone, the MPP and MVP were highest at half rate: 3.5 and 768.5 for SF, 0.7 and 146.7 for FF1 and 1.1 and 240.5 for FF2 making this the economic rate for application of all the fertilizers. In Meru site, for all the fertilizers, SF, FF1 and FF2, the optimum rate to apply is the double rate. This is because they had the highest MPP and MVP values: 7.9 and 1736.5 for SF, 1.3 and 290.4 for FF1 and 3.7 and 806.7 for FF2. 
Table 4. Productivity of clones TRFK 31/8, TRFK 6/8 \& EPK D99/10 at different fertilizers and rates of application

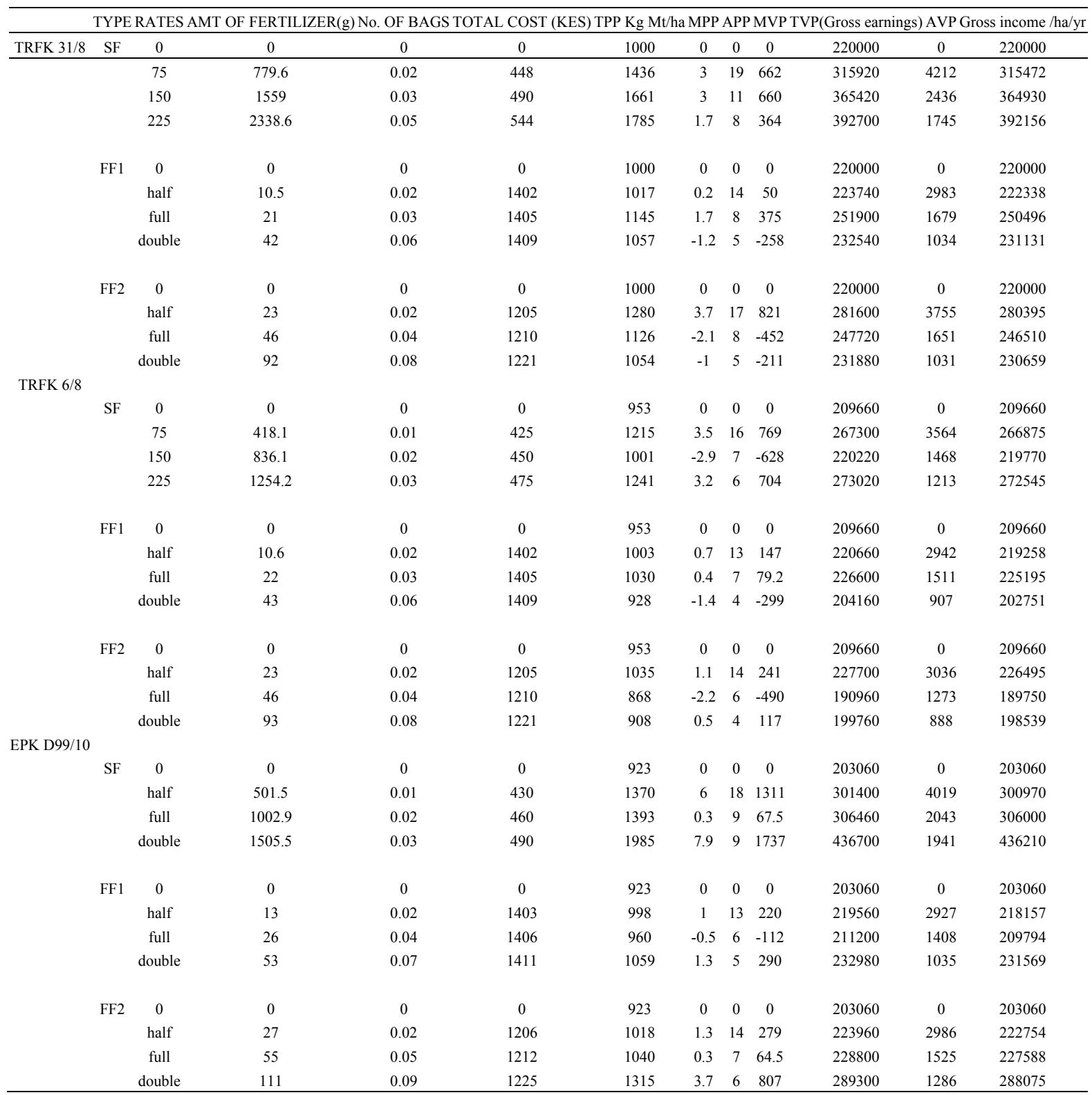

The profitability of the three fertilizers under study was analyzed in Table 4 above, by obtaining the gross profit/ha/year for a particular rate. In this case, the cost of production included the prices of the fertilizers and the cost of labor. For the soil SF the profitable rate was found to be the double rate for all the three clones. Double rates gave the highest gross profit/ha/year at KES 392,156, KES 272,545, and KES 436,210 for the three sites. FF1's profitable rate was the full rates for Kericho and Kirinyaga sites at a gross profit/ha/year of KES 250,496 and KES 225,195 respectively and double rates for Meru site (KES 231,569). FF2 profitable rate was the half rates for clones TRFK 31/8 with gross income/ha/year KES 280,395 and TRFK 6/8, KES 226,495 while clone EPK D99/10's was the double rates, at a gross income of KES 288,075 . The rate of fertilizer applied to tea to achieve maximum profit shifts downward when the price of fertilizer increases.

\section{Discussion}

The present study confirms that different clones have different nutritional needs and differ in their abilities to absorb nutrients even when the agronomic practices are similar, which is depicted in their yield response to varying fertilizer application rates and the fertilizer types applied as well. This was demonstrated herein where two sites Kericho (clone TRFK 31/8) and Meru (clone EPK D99/10) showed significant yield increases while in 
Kirinyaga site (clone TRFK 6/8) there is no response to any of the fertilizer types applied. Previous studies corroborate these findings where they reported varying response in yield, shoot population density, and growth of tea genotypes to different environments including temperature and altitude (Ng'etich \& Stephens, 2001; Omwoyo et al., 2014; Owour et al., 2011). Clone TRFK 31/8 and clone EPK D99/10 are known to be cold and drought resistant while clone TRFK 6/8 is not and this may explain the unresponsiveness of clone TRFK 6/8 during this trial period which was occasioned by cases of hail, frost and drought. From Table 2, the composition of the 3 fertilizers types differed markedly with the SF fertilizers having higher amounts of the NPK as compared to the foliar fertilizers which could explain the higher yields. For instance, in Kericho, the composition of applied fertilizers for half rates was $2.5 \mathrm{~g} \mathrm{~N}, 1.5 \mathrm{~g} \mathrm{~K}$ and $1.9 \mathrm{~g}$ P for FF1; $4.6 \mathrm{~g} \mathrm{~N}, 1.2 \mathrm{~g} \mathrm{~K}$ and $1.2 \mathrm{~g} \mathrm{P}$ for FF2; and $97.5 \mathrm{~g} \mathrm{~N}, 19.5 \mathrm{~g} \mathrm{P}$, and $19.5 \mathrm{~g} \mathrm{~K}$ for SF. The rate of change in yields indicated that although the fertilizers were applied at different times and rates, and yields varied significantly, the overall patterns (month to month) of change in yields were similar for each site. This was corroborated by (Drinnan, 2008), who reported that though yields varied significantly between farms and between years, the overall patterns of growth were quite similar in his study. Aside from the nutrients applied, weather elements also greatly influence yields, produced from month to month (Owour et al., 2011), as was observed in this study. There were severe cases of frost and drought which led to very low or no yields in some months. From on-site weather stations, the relative humidity was particularly low, which could have led to 'banjhi' buds, thereby explaining the low yields. Results from a parallel investigation showed significant correlation of yield with nutrient levels (NPK) applied (Njogu et al., 2014a), and also significant increases in levels of total polyphenols for foliar fertilizer applied plots more than $\mathrm{SF}$, and this was notwithstanding the considerable lower amounts of foliar fertilizers applied as compared to the control SF by a factor of 1:5:107 (FF1:FF2: SF) per hectare (Njogu et al., 2014b).

Studies have shown little direct relationship between attainable yield and the most economic which may be due to large variations in residual soil $\mathrm{N}$ due to continuous application of nitrogenous fertilizer over the years (Kiprono et al., 2010), which could have hindered accurate attainment of EONR especially for the foliar fertilizers. However, the findings herein can be utilized in the harmonizing the rates (through adjusting the actual amounts of fertilizers applied upwards) in order to establish a universal optimal rate for foliar fertilizers that does not compromise on quality. This would in turn reduce the frequency of application (FF1 was applied every 2 months, FF2 every 3 months as compared to SF applied yearly) and consequentially maximize productivity and profitability.

\section{Conclusion}

There was significant yield increases after application of FF1 full rate (HSD $=4.9, p \leq 0.05)$, SF's half, full and double rates (HSD $=49,44,19, \mathrm{p} \leq 0.05$ respectively) in Meru site, and SF's half, full and double rates (HSD $=17$, $16,10 \mathrm{p} \leq 0.05$ respectively) in Kericho site. Yields vary largely due to genotypes, environment and management.

The most economic fertilizer rates differed with growing conditions and clones. The economic rates were determined to be full rate for FF1 and SF and half rate for FF2 in Kericho site; half rate all fertilizer types Kirinyaga site; double rate for FF2 and SF and full rate for FF1 in Meru site. The profitable rates were: double rate for SF across all sites and for FF1 and FF2 in Meru site; full rate for FF1 and half rate for FF2 in Kericho and Kirinyaga sites respectively.

\section{Acknowledgements}

The authors would like to appreciate the Tea Research Foundation of Kenya (TRFK) for providing research facilities, trial sites and the University of Nairobi for providing a scholarship that enabled the successful completion of this research work.

\section{References}

Anonymous. (2002). Tea Growers Hand Book (5th Ed.). Kericho. The Tea Research Foundation of Kenya, Kijabe Printing Press, Kijabe, Kenya.

Ayiemba, P., \& Nyabundi, K. (2010). Economic impacts of nitrogenous fertilizer use in tea cultivation. TRFK Quarterly Bulletin, 15, 4.

Belanger, G., Walsh, J., Richards, J., Milburn, P., \& Ziadi, N. (2000). Comparison of three statistical models describing potato yield response to nitrogen fertilizer. Agronomy Journal, 92, 902-908. http://dx.doi.org/10.2134/agronj2000.925902x

Colman, D., \& Young, T. (1989). Principles of Agricultural Economics: Markets and Prices in Less Developed Countries. Cambridge, UK: Cambridge University Press. http://dx.doi.org/10.1017/CBO9780511623509 
De Costa, W., Mohotti, A., \& Wijeratne, M. (2007). Ecophysiology of tea. Braz. J. Plant Physiol, 19(4), $299-332$. http://dx.doi.org/10.1590/S1677-04202007000400005

Drinnan, E. (2008). Fertilizer Strategies for Mechanical Tea Production. RIRDC Publication No 08/030.

Islam, S., Qamar-uz-Zaman, A. S., Ahmad, F., Hussain, S., \& Hamid, F. S. (2012). Effect of foliar spray of varying nitrogen levels on mature tea yield under different agroecological conditions. J. Agric. Res., 50(4), 485-492.

Kiprono, K., Wanyoko, J., Kamau, D., \& Chepng'eno, W. (2010). Economics of Nitrogen Fertilizer Use in Tea. Tea, 31(2), 36-43.

Kyveryga, P., Blackmerb, A., \& Andorris, T. (2007). Disaggregating model bias and variability when calculating economic optimum rates of nitrogen fertilization for corn. Agronomy Journal , 99(4), 1048-1056. http://dx.doi.org/10.2134/agronj2006.0339

Ng'etich, W. K., \& Stephens, W. (2001). Responses of tea to environment in Kenya. 1. Genotype X environment interactions for total dry matter production and yield. Expl Agric., 37, 333-342. http://dx.doi.org/10.1017/S0014479701003052

Njogu, R. E. N., Kariuki, D. K., Kamau, D. M., \& Wachira, F. N. (2014a). Relationship between tea (Camellia sinensis) leaf uptake of major nutrients, nitrogen, phosphorous and Potassium (npk) and leaf anatomy of different varieties grown in the Kenyan highlands. BEST: International Journal of Humanities, Arts, Medicine and Sciences, 2(8), 95-102.

Njogu, R. E. N., Kariuki, D. K., Kamau, D. M., \& Wachira, F. N. (2014b). Effects of foliar fertilizer application on quality of tea (Camellia sinensis) grown in the Kenyan highlands. American Journal of Plant Sciences, 5, 2707-2715. http://dx.doi.org/10.4236/ajps.2014.518286

Omwoyo, W. N., Owuor, P. O., Ongeri, D. M., \& Kamau, D. M. (2014). Effect of genotypes in different environments on micronutrient content of black tea. Journal of Tea Science Research, 4(2), 17-26.

Owour, P., Kamau, D., Kamunya, S. M., Msomba, S., Uwimana, M., \& Okal, A. (2011). Effects of genotype, environment and management on yields and quality of black tea. genetics, biofuels and local farming systems, Sustainable Agriculture Rev, 7(10), 277-307. http://dx.doi.org/10.1007/978-94-007-1521-9_10

TBK. (2010). TBK Statistics. Nairobi: Tea board of Kenya.

TRFK. (1999). TRFK Annual Technical Report. Fertilizer use and plant nutrition. Kericho: Tea research foundation of Kenya.

\section{Copyrights}

Copyright for this article is retained by the author(s), with first publication rights granted to the journal.

This is an open-access article distributed under the terms and conditions of the Creative Commons Attribution license (http://creativecommons.org/licenses/by/3.0/). 